\title{
'Candidatus Odyssella thessalonicensis' gen. nov., sp. nov., an obligate intracellular parasite of Acanthamoeba species
}

\author{
R. J. Birtles, ${ }^{1 \dagger}$ T. J. Rowbotham, ${ }^{2}$ R. Michel, ${ }^{3}$ D. G. Pitcher, ${ }^{4}$ \\ B. Lascola, ${ }^{1}$ S. Alexiou-Daniel ${ }^{5}$ and D. Raoult ${ }^{1}$
}

Author for correspondence: R. J. Birtles. Tel: 0117928 7541. Fax: 01179300543.

e-mail: richard.birtles@bristol.ac.uk

1 Unité des Rickettsies, CNRS
UPRESA 6020, Faculté de
Medécine, 27 Boulevard
Jean Moulin, 13385
Marseille cédex 5, France
2 Public Health Laboratory,
Bridle Path, York Road,
Leeds LS15 7TR, UK
3 Central Institute of Federal
Armed Forces Medical
Service, Microbiology
(Parasitology), PO Box
7340, D-56065, Koblenz,
Germany
4 Atypical Pneumonias Unit,
Respiratory and Systemic
Infections Laboratory,
Central Public Health
Laboratory, 61 Colindale
Avenue, London NW9 5HT,
UK
5 Department of
Microbiology, School of
Medicine, Aristotelian
University of Thessaloniki,
Thessaloniki 54006, Greece

\begin{abstract}
An intracellular bacterium, strain L13, was observed infecting an environmental isolate of an Acanthamoeba species. The bacterium could not be recovered on axenic medium but was recovered and cultivated in vitro using cultures of Acanthamoeba polyphaga. The 16S rRNA gene sequence of L13 was found to be new, sharing less than $84 \%$ similarity with other sequences in the GenBank/EMBL database. L13 was found to be a member of the $\alpha$-Proteobacteria, sharing an evolutionary line of descent with a group of uniquely obligate intracellular organisms comprised of Caedibacter and Holospora species and the NHP bacterium. Viable bacteria appeared to be highly motile within amoebae. Ultrastructural analysis of the bacterium demonstrated that it is rod-shaped and possesses a typical Gram-negative cell wall, but has no other outstanding features except small vesicle-like structures often associated with the outer surface of each bacterium. The host range of L13 was found to be limited to the genus Acanthamoeba. In A. polyphaga, L13 infection was slow to manifest when cultures were incubated below $30^{\circ} \mathrm{C}$, but at higher temperatures bacteria multiplied prolifically and induced host cell lysis. The protein profile of the bacterium purified from the amoebae was assessed by SDS-PAGE and its G+C content was estimated to be $41 \mathrm{~mol} \%$. Although these results support the proposal of L13 as a new species, its obligate intracellular nature prevented isolation of a definitive type strain. L13 is therefore proposed as 'Candidatus Odyssella thessalonicensis' gen. nov., sp. nov.
\end{abstract}

Keywords: 'Candidatus Odyssella thessalonicensis', obligate intracellular bacterium, $\alpha$-Proteobacteria, Acanthamoeba

\section{INTRODUCTION}

Among the diverse bacteria that make up the staple diet of free-living protozoa, some have evolved the ability to survive grazing and exploit their predators as hosts. Over the past 25 years there have been numerous observations of such bacteria, although for most, their obligate intracellular nature has prevented their axenic culture and has thus excluded them from charac-

\footnotetext{
† Present address : Department of Pathology and Microbiology, School of Medical Sciences, University of Bristol, Bristol BS8 1TD, UK.

The GenBank/EMBL accession number for the 16S rRNA sequence of 'Candidatus Odyssella thessalonicensis' strain L13 is AF069496.
}

terization and taxonomic placement (Fritsche et al., 1993; Hall \& Voelz, 1985; Michel et al., 1995b; Preer \& Preer, 1984; Proca-Ciobanu et al., 1975). Such organisms have generally been distinguished from one another solely on the basis of either morphological features or differences in host specificity. The advent of molecular identification methods, involving PCRbased amplification then sequence analysis of $16 \mathrm{~S}$ rRNA genes, has permitted meaningful taxonomic assessments to be applied to these organisms for the first time. Recent studies have demonstrated the evolutionary diversity of intraprotozoal bacteria, with meaningful phylogenetic placements being proposed for amoeba-infecting Legionella species and Chlamydia-like organisms (Amann et al., 1997; Birtles 
et al., 1996), and the ciliate-infecting species Holospora obtusa and Caedibacter caryophilus (Amann et al., 1991; Springer et al., 1993).

Such taxonomic studies have been accompanied by in vitro demonstrations of the ability of a number of recognized human pathogens to survive in or exploit protozoan hosts. Pathogens including Legionella pneumophila, Listeria monocytogenes, Vibrio cholerae, Pseudomonas aeruginosa, Burkholderia pickettii and Edwardsiella tarda have been shown to be able to multiply within free-living amoebae (King \& Shotts, 1988; Ly \& Müller, 1990; Michel et al., 1995a; Michel \& Hauröder, 1997; Rowbotham, 1980; Thom et al., 1992), whereas other species have been shown to be able to survive protozoal uptake and to be viably maintained within them (Jardin, 1975; King et al., 1988; Tyndall et al., 1991). Taken together, these reports signify an increased awareness of the role protozoa are likely to play in the environmental maintenance of a spectrum of micro-organisms, and thus the importance of their study.

In this paper we characterize a novel acanthamoebal parasite and, on the basis of this characterization, propose it as a member of a new genus under the name 'Candidatus Odyssella thessalonicensis' gen. nov., sp. nov.

\section{METHODS}

Primary isolation of L13. Microscopic examination of a water sample collected from the drip-tray of the air conditioning unit of a hospital in Thessalonika, Greece, revealed an Acanthamoeba sp. infected with rod-shaped bacteria. The recovery and cultivation of these bacteria in Acanthamoeba polyphaga Linc Ap-1 (Fallon \& Rowbotham, 1990) was achieved as previously described for legionellae (Birtles et al., 1996).

Axenic culture of L13 was attempted by lysing and then inoculating infected amoebae onto a range of media, including buffered charcoal yeast extract agar, trypticase soy agar, heated horse blood agar, Columbia blood agar, chocolate agar, chocolate polyvitex agar, McConkey's agar and nutrient agar. Inoculated media were incubated at ambient temperature and at $37^{\circ} \mathrm{C}$ under aerobic and anaerobic conditions for up to 2 weeks.

Morphological characteristics. The microscopic appearance of L13 within infected amoebae was determined by Gimenez staining. Ultrastructural analysis of L13 was achieved using transmission electron microscopy. A 4-d-old culture of $A$. polyphaga, observed to be heavily infected with L13 by Gimenez staining, was harvested by centrifugation at $5000 \mathrm{~g}$ for $10 \mathrm{~min}$, washed twice in Page's amoebal saline (PAS; Page, 1976), then pre-fixed in $2.5 \%(\mathrm{v} / \mathrm{v})$ gluteraldehyde in PAS for $2 \mathrm{~h}$ at $4{ }^{\circ} \mathrm{C}$. Amoebae were harvested again as above, washed twice in PAS, dehydrated in an ethanol series $(70,90$ and $100 \%, v / v)$ and embedded in Epon 812. Thin transverse sections were cut using an LKB Ultratome III microtome, then attached to microscope grids and stained with a saturated solution of methanol/uranyl acetate and lead citrate in water. Grids were examined using JEOL JEM 1200EX apparatus.
Host range of L13. The host range of L13 was assessed in 23 strains of free-living amoebae. These strains, which belong to 19 species and nine genera, are listed in Table 1. All amoebae were isolated and identified by R. Michel, except Naegleria gruberi CCAP1518/1 ${ }^{\mathrm{e}}$ and Naegleria lovaniensis $\mathrm{Aq} / 9 / 1 / 4 \mathrm{D}$, which were kindly provided by Dr J. De Jonckheere, Wetenschappelik Institut voor Volksgezondheid-Louis Pasteur, Brussels, Belgium, Balamuthia mandrillaris, kindly provided by $\mathrm{Dr} \mathrm{K}$. Janitschke, Robert Koch Institut, Berlin, Germany, and the Acanthamoebae group III Rink strain, kindly provided by Dr H. Seitz, Institut für Medizinische Parasitologie, Bonn, Germany. Two protocols were used to determine host range, one for amoebae which could be maintained in vitro in axenic media and one for those which could only be maintained in the laboratory through grazing on bacterial lawns (see Table 1). For both methods, an L13-infected culture of $A$. polyphaga was harvested by centrifugation at $5000 \mathrm{~g}$ for $10 \mathrm{~min}$. The pellet was resuspended in SCGYE medium (De Jonckheere, 1977), frozen for $3 \mathrm{~h}$ at $-20^{\circ} \mathrm{C}$ and thawed rapidly in a water bath at $37^{\circ} \mathrm{C}$. Liberated bacteria were separated from amoebal debris by passage through a $1 \cdot 2 \mu \mathrm{m}$ filter (Minisart NML; Sartorius) and the filtrate was used immediately to seed cultures of amoebal species, grown either in SCGYE medium or on lawns of enterobacteria cultivated on NN agar (NNA) plates (Page, 1976). Infection of each host species was monitored by microscopic examination using phase-contrast microscopy. If neither infected cells nor any marked reduction in amoebal numbers (which may have resulted from the action of the parasite) were observed after $21 \mathrm{~d}$ incubation at $30^{\circ} \mathrm{C}$, the host was considered resistant to L13 infection.

Effect of temperature on bacterial virulence. Cell culture flasks (Rowbotham et al. 1983) containing $20 \mathrm{ml} \mathrm{PYG} \mathrm{were}$ seeded with $1.5 \times 10^{3} \mathrm{~A}$. polyphag $a$ then incubated at 24,30 , 32 or $37^{\circ} \mathrm{C}$. After $3 \mathrm{~d}$ incubation, the concentration of intact amoebae in each flask was determined. This was achieved by first shaking the flask to disrupt the monolayer, then removing $200 \mu \mathrm{l}$ suspension. The suspension was diluted $1: 3$ by the addition of equal volumes of PAS and trypan blue (Sigma), then transferred to a counting chamber. The number of amoebae within each grid of the chamber was assessed by microscopic observation using $\times 20$ objective and $\times 10$ eyepiece lenses. At least three grids were counted for each sample. Estimates were repeated on day 4, after which cultures were split into two $10 \mathrm{ml}$ aliquots in new $20 \mathrm{~cm}^{2}$ flasks and one was seeded with L13. The inoculum used was $200 \mu$ of a 500 amoeba $\mu 1^{-1}$ suspension drawn from a 3-d-old culture of $A$. polyphaga infected with L13 (incubated at $30^{\circ} \mathrm{C}$ ). Microscopic observation of this culture following Gimenez staining indicated about 1 in 30 amoebae were infected with 20-50 bacteria within each amoeba, thus the infecting inoculum contained in the order of $6.6 \times 10^{4}-$ $1.5 \times 10^{5}$ intracellular bacteria. Following inoculation, the amoebal concentrations within infected and uninfected cultures at each of the four temperatures were monitored each day (as described above) for the next $12 \mathrm{~d}$, then subsequently at 15,18 and $21 \mathrm{~d}$.

Amplification and base sequence determination of the $16 \mathrm{~S}$ rRNA gene of L13. A crude DNA extract was prepared from a heavily infected amoebal culture as described previously (Birtles et al., 1996). This extract was then used as template in a PCR incorporating broad-spectrum 16S rRNA gene primers (Lane, 1991). The amplification product was purified using reagents of the QIAquick purification kit (Qiagen), according to manufacturer's instructions, for use as template 
Table 1. Results of L13 co-cultivation tests using different strains of free-living amoebae

\begin{tabular}{|c|c|c|c|}
\hline Species & Strain & $\begin{array}{c}\text { Intracytoplasmic } \\
\text { multiplication } \\
\text { of L13 }\end{array}$ & $\begin{array}{c}\text { Growth } \\
\text { requirement }\end{array}$ \\
\hline Acanthamoeba polyphaga & Linc A1 & +++ & SCGYE \\
\hline Acanthamoeba lenticulata (group III) & 89 & + & SCGYE \\
\hline Acanthamoeba lenticulata (group III) & 45 & ++ & SCGYE \\
\hline Acanthamoeba lenticulata (group III) & 118 & ++ & SCGYE \\
\hline Acanthamoeba spp. (group II) & HLA & ++ & SCGYE \\
\hline Acanthamoeba spp. (group II) & Rink & + & SCGYE \\
\hline Acanthamoeba castellanii (group II) & $\mathrm{C} 3$ & +++ & SCGYE \\
\hline Acanthamoeba quinalugdunensis (group II) & $312-1$ & ++ & SCGYE \\
\hline Acanthamoeba comandoni (group I) & Am23 & - & NNA \\
\hline Acanthamoeba comandoni (group I) & WBT & - & NNA \\
\hline Naegleria gruberi & CCAP $1518 / 1 \mathrm{e}$ & - & SCGYE \\
\hline Naegleria gruberi & aflag & - & SCGYE \\
\hline Naegleria lovaniensis & $\mathrm{Aq} / 9 / 1 / 4 \mathrm{D}$ & - & SCGYE \\
\hline Willaertia magna & NI4CL1 & - & SCGYE \\
\hline Willaertia magna & JIIIPW & - & SCGYE \\
\hline Vahlkampfia ustiana & A1PW & - & NNA \\
\hline Vahlkampfia ovis & Rhodos & - & NNA \\
\hline Vahlkampfia avara & TWA & - & NNA \\
\hline Hartmannella vermiformis & Os/101 & - & SCGYE \\
\hline Comandonia operculata & WBT & - & NNA \\
\hline Vannella spp. & Aun Vano & - & NNA \\
\hline Saccamoeba limax & SL1CL1 & - & NNA \\
\hline Balamuthia mandrillaris & CDC VO39 & - & SCGYE \\
\hline
\end{tabular}

in cycle sequencing reactions. Sequencing reactions used reagents of the Amplicycle kit (Pharmacia), incorporating fluorescein 5 -labelled primers. The primers employed were universal eubacterial 16S rRNA sequencing primers (Lane, 1991). The products of sequencing reactions were resolved on $0.35 \mathrm{~mm}$ Readimix acrylamide gels (Pharmacia), then detected and converted into sequence data using an ALF automated sequencer (Pharmacia) and associated software. The nucleotide sequence of the $16 \mathrm{~S}$ rRNA gene was determined in both forward and reverse directions and in triplicate.

Phylogeny of L13. The primary sequence of the $16 \mathrm{~S}$ rRNA gene of L13 was generated by aligning and then combining the sequences generated by each primer using DNASIS (Hitachi Software Engineering). The validity of this sequence was verified by assessing theoretical nucleotide base pairing in a eubacterial secondary structure model (Neefs et al., 1993). The similarity values between the verified L13 sequence and those of other eubacterial $16 \mathrm{~S}$ rRNA sequences were assessed using a BLAST search of the GenBank/EMBL databases (24 June 1998).

All phylogenetic studies of the L13 16S rRNA gene sequence were carried out on programs supported within the BISANCE workstation (Dessen et al., 1990). The sequence was aligned with those of other chosen Proteobacteria using the multisequence alignment program CLUSTAL (Higgins et al., 1992). Phylogenetic inferences were derived from this alignment once overhanging sequences at either end of the alignment, gaps and ambiguities had been removed. Three approaches were used, all of which used progams within the PHYLIP suite
(J. Felsenstein, University of Washington, Seattle, USA). First, a matrix of evolutionary distances was generated from the alignment using DNADIST under the assumptions of Jukes \& Cantor (1969) and a phylogenetic tree was derived from this matrix using the criteria of Fitch \& Margoliash (1967) (FITCH). Second, the alignment was subjected to parsimony analysis (DNAPARS) and third, maximum-likelihood analysis (DNAMLK). The stabilities of the topologies proposed by each approach were assessed by bootstrap analysis using the programs SEQBOOT and CONSENSE to yield a strict majorityrule consensus tree based on 200 samples.

Purification of L13 from A. polyphaga cultures. The entire procedure for the recovery of $\mathrm{L} 13$ from infected $A$. polyphaga was carried out at $4^{\circ} \mathrm{C}$. L13-infected $A$. polyphaga was harvested from ten cultures $(40 \mathrm{ml})$ by centrifugation at $10400 \mathrm{~g}$ for $12 \mathrm{~min}$ at $4{ }^{\circ} \mathrm{C}$. Pellets from each harvest were then resuspended and pooled into $10 \mathrm{ml}$ PAS. This suspension was centrifuged at $300 \mathrm{~g}$ for $15 \mathrm{~min}$ to pellet intact amoebae, which were then resuspended in $5 \mathrm{ml}$ PAS and disrupted by sonication at $4{ }^{\circ} \mathrm{C}$ for $2 \mathrm{~min}$. The efficiency of this step was assessed by centrifugation at $300 \mathrm{~g}$ for $15 \mathrm{~min}$ : if a pellet reformed, sonication was repeated. When a pellet was no longer formed, all the supernatants were pooled, centrifuged at $10400 \mathrm{~g}$ for $12 \mathrm{~min}$ at $4{ }^{\circ} \mathrm{C}$ and the pellet was resuspended in $10 \mathrm{ml}$ PAS. This suspension was then layered onto an equal volume of $25 \%(\mathrm{w} / \mathrm{v})$ sucrose in PAS and centrifuged at $8000 \mathrm{~g}$ for $30 \mathrm{~min}$. The pellet was washed twice with PAS, resuspended in $2 \mathrm{ml}$ PAS, then carefully layered onto a $45,36,28 \%(\mathrm{w} / \mathrm{v}$ in PAS) renograffin gradient. The gradient was centrifuged at $25000 \mathrm{~g}$ for $60 \mathrm{~min}$, then bacteria were recovered from the $45: 36 \%$ 
(intact bacteria) and 36:28\% (broken bacteria) interfaces using a spinal punction needle. These bacteria were then washed twice in PBS, resuspended in PBS and stored at $-20^{\circ} \mathrm{C}$ until required. The presence and purity of recovered bacteria were assessed by Gimenez staining.

Analysis of cellular proteins. Purified bacteria, unpurified bacteria and uninfected amoebae (each at a concentration of 20-50 $\mu \mathrm{g}$ protein) were each mixed $1: 1$ with Laemmli buffer (0.625 M Tris/HCl, $\mathrm{pH} \mathrm{8.0;2 \% ,} \mathrm{w/v,} \mathrm{SDS;} \mathrm{5 \% ,} \mathrm{v/v,}$ mercaptoethanol; $10 \%, \mathrm{v} / \mathrm{v}$, glycerol; $0.002 \%, \mathrm{w} / \mathrm{v}$, bromophenol blue). This mixture was then treated in one of three ways, being either (i) held on ice, (ii) held at room temperature for $30 \mathrm{~min}$ or (iii) boiled for $5 \mathrm{~min}$. These preparations were then subjected to SDS-PAGE as described by Laemmli (1970) using a 3.0 \% stacking gel with $0 \cdot 5 \%$ SDS and a $15 \%$ resolving gel. Separated proteins were visualized by staining with Coomassie brilliant blue. Prestained SDSPAGE standards (Bio-Rad) were included for estimation of protein band sizes.

Extraction of DNA and estimation of mean base composition. Purified L13 cells were resuspended in $1 \mathrm{ml}$ TNE buffer (10 mM NaCl, $10 \mathrm{mM}$ EDTA, $10 \mathrm{mM}$ Tris/HCl, $\mathrm{pH} 8 \cdot 0$ ) containing $0.5 \% \mathrm{SDS}$ and $100 \mu \mathrm{g}$ proteinase $\mathrm{K} \mathrm{ml}^{-1}$. The suspension was incubated at $37^{\circ} \mathrm{C}$ for $30 \mathrm{~min}$ then $5 \mu \mathrm{l} \mathrm{mg}$ DNase-free RNase $\mathrm{ml}^{-1}$ was added and incubation was continued for a further $30 \mathrm{~min}$. DNA was extracted from the lysed cell suspension using, sequentially, TE buffer $(10 \mathrm{mM}$ Tris/HCl, 1 mM EDTA, pH 8.0) saturated with phenol, phenol/chloroform/isoamylalcohol (25:24:1, by vol.) and finally chloroform. Purified DNA was precipitated from the final aqueous phase by addition of $10 \%(\mathrm{v} / \mathrm{v}) 3 \cdot 3 \mathrm{M}$ sodium acetate and 2 vols ice-cold absolute ethanol. After washing in ethanol, the DNA was dried, resuspended in TE buffer and quantified spectrophotometrically.

The base composition of extracted DNA was estimated spectrophotometrically by the thermal denaturation temperature method as described by Owen et al. (1978). The $\mathrm{G}+\mathrm{C}$ content was calculated from the denaturation temperature and expressed relative to the control value of a previously calculated value of $50.9 \mathrm{~mol} \%$ for Escherichia coli NCTC 9001. The estimation was carried out in triplicate.

Nucleotide sequence accession numbers. The following eubacterial 16S rRNA gene sequences were retrieved from the GenBank database for inclusion in this study: Afipia felis, M65248; Agrobacterium tumefaciens, M11223; Azospirillum lipoferum, Z29619; Bartonella bacilliformis, X60042; Beijerinckia indica, M59060; C. caryophilus, X71837; Ehrlichia sennetsu, M73225; Erythrobacter longus, M59062; Escherichia coli, J01695; H. obtusa, X58198; Legionella brunensis, Z32636; Magnetospirillum magnetotacticum, M58171; NHP bacterium, U65509; Rhodobacter capsulatus, D16428; Rhodobacter sphaeroides, D16425; Rhodospirillum rubrum, D30778; Rickettsia prowazekii, M21789; Rickettsia rickettsii, M21293; Sphingomonas paucimobilis, D13725; Wolbachia pipientis, X61768.

\section{RESULTS}

\section{Morphological characteristics}

Observation of infected amoebae using light or phasecontrast microscopy revealed the presence of large numbers of highly mobile rod-shaped bacteria within the cytoplasm. Gimenez staining of heat-fixed infected

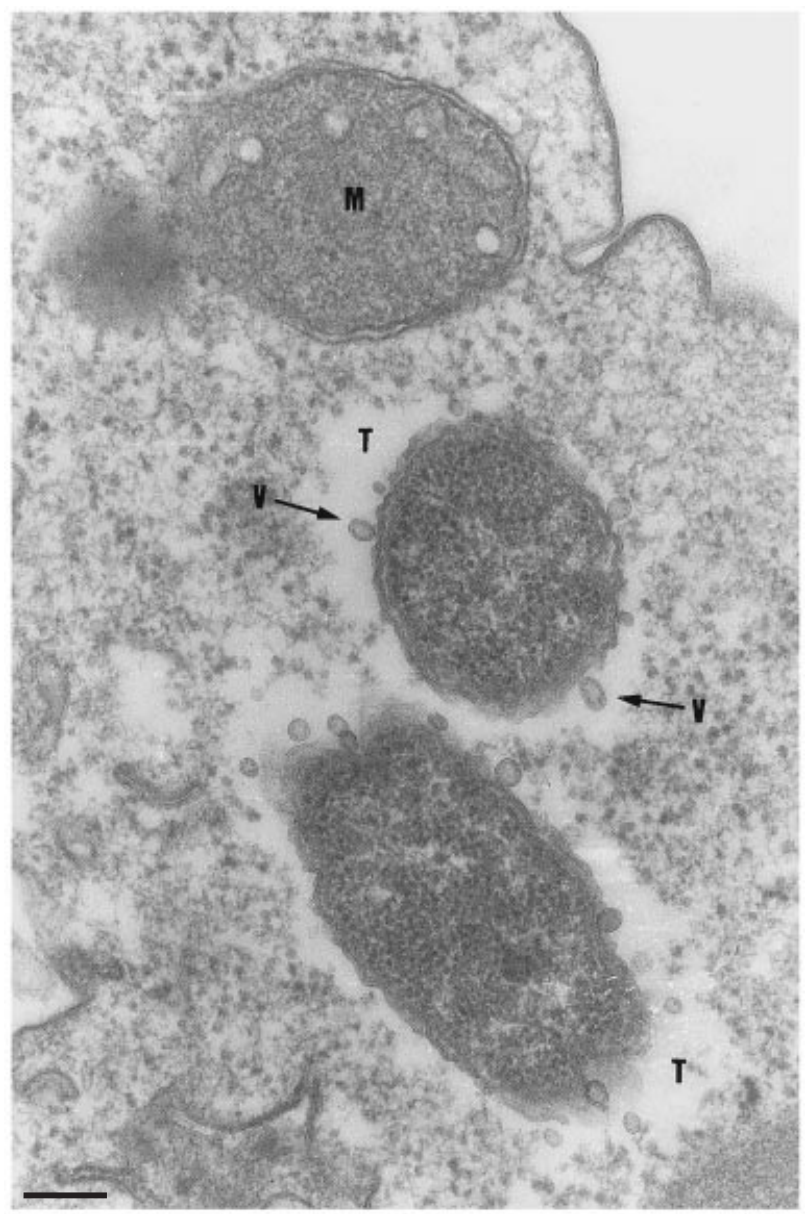

Fig. 1. Transmission electron micrograph of a section $A$. polyphaga infected with L13, demonstrating the ultrastructural features of the bacterium. V, vesicle-like structures associated with bacterial outer membrane; $T$, electron-translucent halo surrounding bacteria; $\mathrm{M}$, amoebal mitochondrion. Bar, $0.25 \mu \mathrm{m}$.

amoebae confirmed the intracytoplasmic presence of these bacteria. Electron microscopic observation revealed details of their ultrastructure (Fig. 1). Bacteria appeared to lie free within the cytoplasm, but often surrounded by an electron-translucent area (see Fig. 1). The bacterial cell wall appeared typically Gramnegative, although often vesicle-like structures were closely associated with it. Vesicles also appeared detached from the bacterial surface, lying within the surrounding translucent zone (Fig. 1). L13 was estimated to be typically $0 \cdot 2-0 \cdot 5 \mu \mathrm{m}$ wide and $0 \cdot 7-1 \cdot 0 \mu \mathrm{m}$ long, although some degree of polymorphism was observed. On release from lysed host amoebae, L13 appeared to take on a more elongated morphology (data not shown). Electron microscopy failed to identify any flagella on L13 despite observation of cocultures of different ages and incubated at different temperatures. L13 appeared to lack flagella even when released following host-cell lysis (data not shown). No specific features could be observed within the bacteria. 


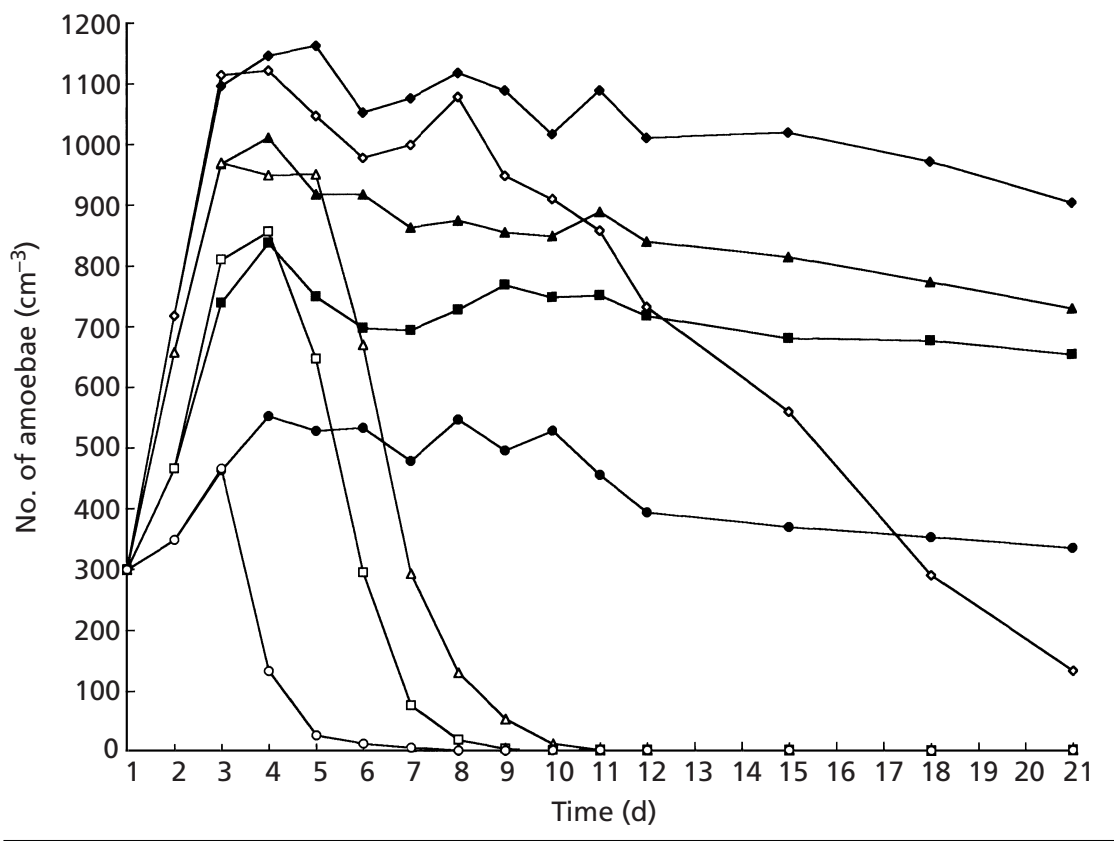

Fig. 2. Effect of temperature on the growth and survival of uninfected (filled symbols) and L13-infected (open symbols) $A$. polyphaga. $\diamond, \diamond, 22^{\circ} \mathrm{C} ; \boldsymbol{\Delta}, \triangle, 30^{\circ} \mathrm{C} ; \mathbf{\square}, \square, 32{ }^{\circ} \mathrm{C}$; $0,0,37^{\circ} \mathrm{C}$.

\section{Host range}

Of the 23 strains of free-living amoebae in which cultivation of L13 was attempted, only those belonging to groups II and III of the genus Acanthamoeba were susceptible to infection (Table 1). Multiplication of L13 occurred best in A. polyphaga and Acanthamoeba castellanii. Acanthamoeba comandoni, a member of the group I Acanthamoeba species, was the only member of the genus tested which was not susceptible to infection.

\section{Effect of temperature on bacterial virulence}

A. polyphaga grew at temperatures between 22 and $37{ }^{\circ} \mathrm{C}$, but rapidly encysted at $42{ }^{\circ} \mathrm{C}$. As demonstrated in Fig. 2, lower temperatures favoured better growth of the amoeba, with cultures incubated at $22^{\circ} \mathrm{C}$ being over twice as dense as those grown at $37^{\circ} \mathrm{C}$. Higher temperatures enhanced the virulence of L13. At $37^{\circ} \mathrm{C}$ virtually all amoebae were lysed within $5 \mathrm{~d}$ of bacterial infection, whereas at $22^{\circ} \mathrm{C}$ intact amoebae could be observed over 3 weeks post-infection. Even growth at 32 or $30^{\circ} \mathrm{C}$ resulted in destruction of virtually all amoebae within $10 \mathrm{~d}$ of bacterial infection. At all of the three higher temperatures tested, the rate of decline of intact amoebae in infected cultures appeared to be very similar and very rapid (taking 3-4d), and decreasing temperature served only to delay the onset of this decline. However, at $22{ }^{\circ} \mathrm{C}$ the rate at which amoebae were destroyed was markedly slower; after an initial sharp rise, the number of intact amoeba fell gradually throughout the $21 \mathrm{~d}$ of the experiment. Importantly, viable L13-infected amoebae could be recovered from the cultures incubated at $22{ }^{\circ} \mathrm{C}$ over 4 months after the experiment described above was completed (data not shown).

\section{S rRNA gene amplification and analysis}

A primary 16S rRNA gene sequence of $1454 \mathrm{bp}$ was determined for L13 and its validity was supported by secondary structure modelling (data not shown). A FASTA search of the GenBank database indicated a proteobacterial origin for the bacterium. The $16 \mathrm{~S}$ rRNA gene of L13 was found to be most similar to those of members of the $\alpha$-Proteobacteria, sharing between 80 and $84 \%$ similarity. However, within this subclass, L13 did not share a specifically high similarity with any particular species, nor with the members of any particular group.

The alignment used as a basis for phylogenetic analysis comprised the L13 sequence, the sequences of diverse representatives of the $\alpha$-Proteobacteria and those of two $\gamma$-Proteobacteria (Escherichia coli and Legionella brunensis). The latter two were included as outgrouping species on which trees could be rooted. The 16S rRNA gene sequences available for some of the $\alpha$ Proteobacteria were not as complete as that obtained in this study, usually through the lack of data at the $3^{\prime}$ extremity of the gene. Some sequences also included a relatively large number of base ambiguities. The length of the alignment was thus limited to $1177 \mathrm{bp}$. An evolutionary distance matrix was calculated from pairwise comparison of sequences in this alignment and a phylogenetic tree (Fig. 3) was inferred from this matrix. The inclusion of L13 had no significant effect on the overall topology of this tree, which is in concordance with those previously proposed (e.g. Loy et al., 1996). The evolutionary position proposed for L13 was within a cluster of obligate intracellular bacteria, which, although within the $\alpha$-subclass of the Proteobacteria, lies apart from any of the four recognized subgroups $(\alpha 1-4)$ and the lineage carrying 


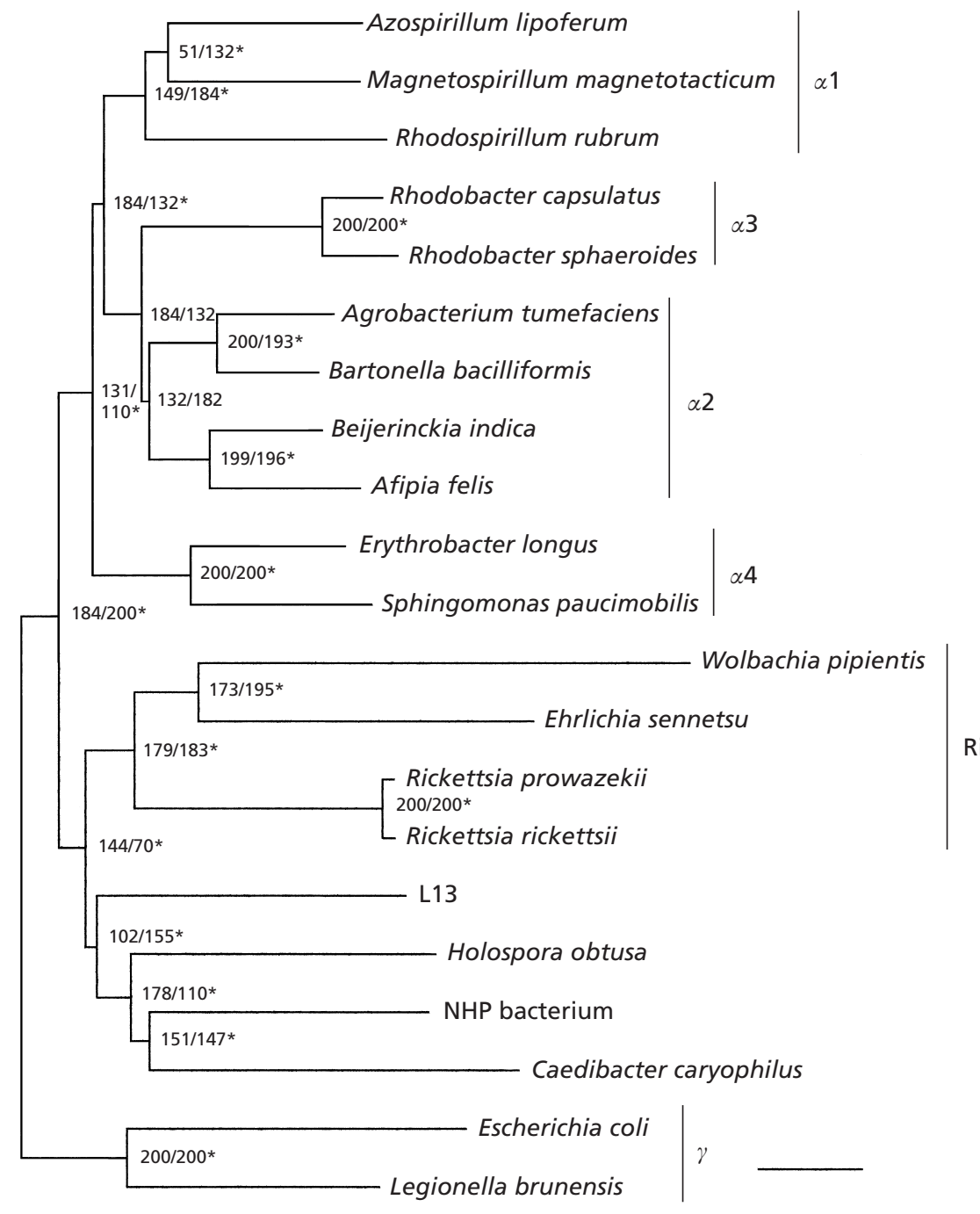

\begin{abstract}
Fig. 3. Phylogenetic tree comparing $\mathrm{L} 13$ with various members of the $\alpha$ - and $\gamma$ Proteobacteria. The numbers at each node are the results of bootstrapping; each value is derived from 200 samples as an indication of semi-statistical support for the proposed branching order. The first value is derived from distance matrix analysis and the second value is derived from parsimony analysis. Values of $>140$ (70\% of samples) are usually considered as indicating good support for the proposed branching order at that node. An asterisk appearing after the two bootstrap values indicates that the cluster supported by that node was also proposed by maximum-likelihood analysis. The vertical bars to the right of the tree indicate representatives of various subclasses of the Proteobacteria $(\alpha 1-\alpha 4, \gamma)$ and representatives of the Rickettsiales (Ri). Scale bar, $0.04 K_{\text {nuc }}$
\end{abstract}

members of the Rickettsiales (Fig. 3). A specific evolutionary relatedness between L13 and the three other members of the identified cluster (H. obtusa, C. caryophilus and the NHP bacterium) was also supported by parsimony- and maximum-likelihoodbased phylogenetic inferences, although in none of these three reconstructions was there overwhelming support from bootstrapped sampling (see Fig. 3). Likewise, although all three inferences suggested that the L13-containing cluster shared specific evolutionary descent with the Rickettsiales lineage, bootstrap support was again only moderately strong. However, within the cluster defined above, L13 branched apart from the lineage carrying the other three members, a divergence which was well supported (Fig. 3).

\section{Analysis of cellular proteins}

SDS-PAGE profiles obtained for L13 are presented in Fig. 4 . The profiles obtained for purified bacteria were distinct from those of uninfected amoebae, demonstrating the success of the purification protocol used.
Unpurified bacteria yielded a profile which, although dominated by L13-specific bands, also included amoebal proteins. The profiles yielded by untreated bacteria included heavy smears at the top of the gel, indicating the presence of very large proteins that were unable to enter the gel. These profiles also did not have clearly distinguishable bands larger than $36 \mathrm{kDa}$ with the exception of one of an estimated $39 \mathrm{kDa}$. However, below this size numerous strongly staining bands were present. There was little difference between the profiles derived from intact and broken bacteria, although it appeared that a protein of approximately $33 \mathrm{kDa}$ was more abundantly liberated from broken cells (Fig. 4). Heat treatment resulted in denaturation of very high molecular mass proteins to yield profiles more complex than those derived from untreated organisms. A number of larger bands appeared in the profiles, including an intensely staining protein of about $50 \mathrm{kDa}$. Two further particularly strongly staining bands were present at approximately 25 and $18 \mathrm{kDa}$, although at least 12 other bands were also discernible. Bacteria incubated with Laemmli buffer at $37^{\circ} \mathrm{C}$ for 


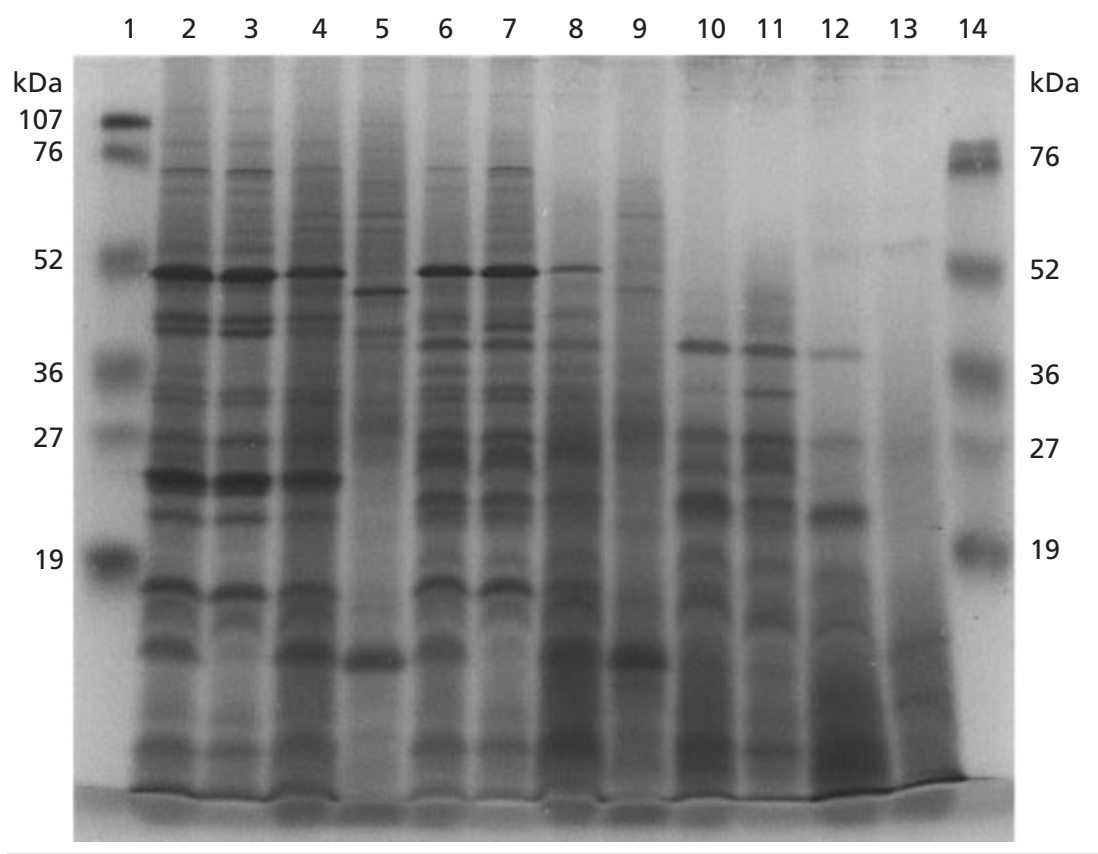

Fig. 4. SDS-PAGE profiles derived from $L 13$ and $A$. polyphaga. Samples in lanes 2-5 were boiled prior to loading, those in 6-9 were held at $37^{\circ} \mathrm{C}$ for $30 \mathrm{~min}$ and those in lanes 10-13 were untreated. Lanes: 2, 6 and 10, purified intact L13; 3, 7 and 11, purified non-intact L13; 4, 8 and $12, A$. polyphaga heavily infected with L13; 5,9 and 13 , uninfected $A$. polyphaga; 1 and 14 , molecular mass markers.

30 min yielded profiles which, in general, consisted both of bands present in profiles derived from untreated bacteria and bands present in profiles derived from boiled bacteria. However, only very few bands were present in profiles derived from both untreated and heat-treated bacteria (see Fig. 4), with the co-migrating bands of approximately 33 and $27 \mathrm{kDa}$ being perhaps the best candidates for heatstable proteins.

\section{Estimate of mean base composition}

The $\mathrm{G}+\mathrm{C}$ content of $\mathrm{L} 13$ was estimated to be $41 \pm 1 \mathrm{~mol} \%$.

\section{DISCUSSION}

The ability to exploit protozoan hosts offers bacteria access to a protected, nutrient-rich niche suitable for long-term survival in the environment. That this opportunity has been seized by a wide spectrum of bacteria is now becoming more apparent. Protozoaincorporating in vitro co-cultivation methods are known to be able to support an increasing number of recognized pathogens and, following the introduction of PCR-based characterization methods, an increasing number of newly recognized obligate intraprotozoal organisms are being reported. In this study we add to this knowledge by reporting the isolation and characterization of another previously unrecognized bacterium.

Although the current taxonomic criteria for the creation of a new species are well-defined (Murray et al., 1990; Stackebrandt \& Goebel, 1994), those required for the proposal of a new genus are more subjective
(Murray et al., 1990). Thus, whereas the moderate level of $16 \mathrm{~S}$ rRNA sequence similarity shared by L13 with previously recognized species can be used to justify its proposal as a new species, that this new species warrants placement in a new genus is another question. Perhaps the best way of resolving this issue is to assess whether L13 can be satisfactorily accommodated within the genera with which it shares most evolutionary homology, namely Holospora and Caedibacter. Although both these genera are comprised endosymbionts of protozoa, these have to date been associated solely with infection of ciliates. Holospora species specifically infect the micronucleus or macronucleus of their Paramecium hosts and possess a life cycle comprised two distinct morphological forms. In a refractile form, the bacteria form short $(1-3 \mu \mathrm{m})$ fusiform rods, which undergo binary fission and give rise to long infective forms of up to $20 \mu \mathrm{m}$ (Preer \& Preer, 1984). The $\mathrm{G}+\mathrm{C}$ content has not been measured for any Holospora species. Caedibacter are moderately sized (up to $1 \mu \mathrm{m}$ diam. and $4 \mu \mathrm{m}$ long) rod-shaped or coccobacilli which are characterized by possession of distinctive refractile inclusions, termed $\mathrm{R}$ bodies. From these descriptions it is clear that L13 is somewhat smaller than Holospora and Caedibacter species and shares none of the distinctive morphological features of either genus. Although somewhat pleomorphic, L13 present a typical Gram-negative rod-like morphology. No elongated forms comparable to Holospora infective forms were observed and no refractile bodies characteristic of Caedibacter were present within L13 bacteria. Furthermore, the host range of L13 was limited to Acanthamoeba species. Although the $\mathrm{G}+\mathrm{C}$ content of L13 was found to be similar to that reported for Caedibacter species (Preer \& Preer, 1984), this cannot 
be used to justify that the organisms share a specific taxonomic relationship. A low $\mathrm{G}+\mathrm{C}$ content is in common with many species both within the $\alpha$ Proteobacteria and beyond. Thus, from these comparisons it is clear that the proposal of a new genus to accommodate L13 is undoubtedly justified.

Whether L13 is the same organism as any of those observed in previous studies is difficult to assess. ProcaCiobanu et al. (1975) reported Acanthamoeba SN endosymbionts which were Gram-negative, intracytoplasmic and of a similar size to L13. An Acanthamoeba endosymbiont (HN-3) described by Hall \& Voelz (1985) was very similar in appearance to the SN endosymbionts but was surrounded by an electron-translucent area, similar in appearance to that of L13. Hall \& Voelz (1985) demonstrated that this translucent area resulted from the presence of bacterial capsular material. Although we have not investigated if the area surrounding L13 is of the same origin, we did note that in several electron micrographs L13 did not possess this translucent halo and that this absence was more common when L13 was cultured at higher temperatures $\left(37^{\circ} \mathrm{C}\right)$. More recently, Fritsche et al. (1993) reported two forms of endosymbionts in Acanthamoeba. One, a coccal form, appeared indistinguishable from ' Candidatus Parachlamydia acanthamoebae' (Amann et al., 1997), whereas the second bore a marked microscopic and ultrastructural resemblance to L13. This organism was, however, reported to be non-motile. The same workers have subsequently reported preliminary $16 \mathrm{~S}$ rRNA sequence data for these two organisms (Gautom \& Fritsche, 1996); the first form was indeed confirmed as sharing high levels of sequence similarity with the sequences of Chlamydia and Parachlamydia species, whereas the second was found to share highest similarity levels with the Rickettsiales. Although distinct from the Rickettsiales, we have shown that L13 may well share an evolutionary lineage with $\alpha$-proteobacterial members of this polyphyletic family and that these species are among those with which L13 shares the highest 16S rRNA similarity levels.

The results we report add to other recent findings in broadening the evolutionary spectrum of bacteria now recognized as being capable of exploiting Acanthamoeba as hosts. The importance of these protozoa to the natural cycles of legionellae is now well-established (Barker \& Brown, 1994) and 16S rRNA methods have been used to demonstrate a diversity of Legionella species which can be recovered using in vitro acanthamoebal co-cultivation methods, but not axenic media (Birtles et al., 1996). More recently, Amann et al. (1997) used phylogenetic methods to demonstrate the Chlamydia-like nature of another endosymbiont and named it 'Candidatus Parachlamydia acanthamoebae'. Thus, it is now apparent that bacteria from at least three distinct lineages have evolved mechanisms for the exploitation of Acanthamoebae. In addition to these well-characterized organisms, other amoebal endosymbionts have been observed, notably an Ehrlichia-like bacteria (Michel et al., 1995b) and even possible Archaea (Hoffmann et al., 1998). In light of these findings, a phylogenetic assessment of such organisms would be interesting and we are pursuing these goals.

Evidence for a wider role of protozoa as natural hosts for pathogenic bacteria is also supported by numerous laboratory studies. Legionella pneumophila, Listeria monocytogenes, Vibrio cholerae, Pseudomonas aeruginosa, Burkholderia pickettii and Edwardsiella tarda have all been shown to be able to multiply within laboratory protozoal cultures (King \& Shotts, 1988; Ly \& Müller, 1990; Michel et al., 1995a; Michel \& Hauröder, 1997; Rowbotham, 1980; Thom et al., 1992), whereas other species, including Mycobacterium leprae, Pseudomonas and Bacillus species, some coliforms and Chlamydia pneumoniae (Jardin, 1975; Tyndall et al., 1991; King et al., 1988; Essig et al., 1997) have been shown to be able to survive protozoal uptake and to be viably maintained within them. Additionally, evidence of the pathogenic potential of ' Candidatus Parachlamydia acanthamoebae' and intra-amoebal legionellae in atypical pneumonia has now been presented (Fry et al., 1991; Birtles et al., 1997). It also appears that such endosymbionts are common. Fritsche et al. (1993) observed intra-Acanthamoeba bacteria in 14 out of $57(24 \%)$ clinical and environmental isolates examined. Taken together, these findings add further weight to previous indications (Amann et al., 1997) that the role of protozoa, and possibly small free-living amoebae in particular, in the epidemiology of human diseases may presently be significantly underrated.

Investigation of the effect of temperature on the virulence of L13 led to some interesting observations. Higher incubation temperatures resulted in enhanced virulence, whereas at $22{ }^{\circ} \mathrm{C}, \mathrm{L} 13$ appeared to form a far more stable relationship with its host. Whether the virulence of L13 itself is enhanced at temperatures over $30{ }^{\circ} \mathrm{C}$, or whether its apparent virulence results from physiological changes within its host is not known. It is clear from our experiments that uninfected $A$. polyphaga did not grow as well at elevated temperatures and these suboptimal conditions may lead to disruption of the host-parasite equilibrium and the onset of bacterial virulence. The longevity of the L13-host relationship at lower temperatures has not been assessed, although we have observed it to be ongoing after 4 months of co-cultivation.

Although we have applied polyphasic methods to the characterization of L13, its obligate intracellular nature has prevented the unequivocal isolation of a unique strain for proposal as the type strain. Thus, according to Murray \& Schleifer (1994), we propose provisional classification of L13 as 'Candidatus Odyssella thessalonicensis' gen. nov., sp. nov. The genus name is derived from the eloquent analogy drawn by Barker \& Brown (1993) of protozoa as 'Trojan horses of the microbial world'. Odysseus is the 
Latin name for the warrior who, according to Greek mythology, thought up the strategy of penetrating the walls of Troy by hiding himself and fellow Greek warriors inside the infamous wooden horse. The species name reflects the location from where the isolate was obtained, the Greek city of Thessalonika.

\section{Description of ' Candidatus Odyssella thessalonicensis' gen. nov., sp. nov.}

'Candidatus Odyssella thessalonicensis' (Od.ys.sel'la. dim. fem. n. pertaining to Odysseus; thess.al.lon'i. cen'sis. M.L. masc. n. adj. pertaining to the Greek city Thessalonika from where the organism was isolated).

Obligate intracellular bacterium of Acanthamoeba species which cannot be cultivated on cell-free media, only by co-cultivation with a number of Acanthamoeba species at temperatures at and below $37^{\circ} \mathrm{C}$. At temperatures over $30{ }^{\circ} \mathrm{C}$ the organism multiplies rapidly destroying its host, whereas at lower temperatures, it is far less virulent. Host range appears limited to group II and III Acanthamoeba species. Organism is motile and microscopic appearance is typically Gramnegative and rod-shaped. Electron microscopy reveals that the organism lies intracytoplasmically and is usually surrounded by an electron-translucent layer in which vesicle-like structures derived from the cell envelope can be observed. The $\mathrm{G}+\mathrm{C}$ content is $41 \mathrm{~mol} \%$. The phylogenetic position, inferred from comparison of the 16S rRNA gene sequence, is within the $\alpha$-Proteobacteria.

\section{REFERENCES}

Amann, R., Springer, N., Ludwig, W., Görtz, H.-D. \& Schleifer, K.-H. (1991). Identification in situ and phylogeny of uncultured bacterial endosymbionts. Nature 351, 161-164.

Amann, R., Springer, N., Schönhuber, W., Ludwig, W., Schmid, E. N., Müller, K.-D. \& Michel, R. (1997). Obligate intracellular bacterial parasites of acanthamoebae related to Chlamydia spp. Appl Environ Microbiol 63, 115-121.

Barker, J. \& Brown, M. R. W. (1994). Trojan horses of the microbial world: protozoa and the survival of bacterial pathogens in the environment. Microbiology 140, 1253-1259.

Birtles, R. J., Rowbotham, T. J., Raoult, D. \& Harrison, T. G. (1996). Phylogenetic diversity of intra-amoebal legionellae as revealed by $16 \mathrm{~S}$ rRNA gene sequence comparison. Microbiology 142, 3525-3530.

Birtles, R. J., Rowbotham, T. J., Storey, C., Marrie, T. J. \& Raoult, D. (1997). Chlamydia-like obligate parasite of free-living amoebae. Lancet 349, 925-926.

De Jonckheere, J. (1977). Use of an axenic medium for differentiation between pathogenic and non-pathogenic Naegleria fowleri isolates. Appl Environ Microbiol 33, 751.

Dessen, P., Fondrat, C., Valencien, C. \& Mugnier, C. (1990). BISANCE: a French service for access to biomolecular sequence databases. Comput Appl Biosci 6, 355-356.

Essig, A., Heinemann, M., Simnacher, U. \& Marre, R. (1997). Infection of Acanthamoeba castellanii by Chlamydia pneumoniae. Appl Environ Microbiol 63, 1396-1399.
Fallon, R. J. \& Rowbotham, T. J. (1990). Microbiological investigations into an outbreak of Pontiac fever due to Legionella micdadei associated with the use of a whirlpool. J Clin Pathol 43, 479-483.

Fitch, W. M. \& Margoliash, E. (1967). Construction of phylogenetic trees. A method based on mutation distances as estimated from cytochrome $c$ sequences is of general applicability. Science 155, 279-284.

Fritsche, T. R., Gautom, R. K., Seyedirashti, S., Bergeron, D. L. \& Lindquist, T. D. (1993). Occurrence of bacterial endosymbiotes in Acanthamoeba spp. isolated from corneal and environmental specimens and contact lenses. J Clin Microbiol 31, 1122-1126.

Fry, N. K., Rowbotham, T. J., Saunders, N. A. \& Embley, T. M. (1991). Direct amplification and sequencing of the 16S rDNA of an intracellular Legionella species recovered by amoebal enrichment from sputum of a patient with pneumonia. FEMS Microbiol Lett 83, 165-168.

Gautom, R. K. \& Fritsche, T. R. (1996). Characterisation of bacterial endosymbiotes of Acanthamoeba spp. In Abstracts of the 7th International Conference on Small Freeliving Amoebae, 7-12th January 1996. Women's and Children's Hospital, North Adelaide, South Australia.

Hall, J. \& Voelz, H. (1985). Bacterial endosymbiotes of Acanthamoeba sp. J Parasitol 71, 89-95.

Higgins, D., Bleasby, A. \& Fuchs, R. (1992). CLUSTAL V: improved software for multiple sequence analysis. Comput Appl Biosci 8 , 188-192.

Hoffmann, R., Michel, R., Müller, K.-D. \& Schmid, E. N. (1998). Archaea like endocytobiotic organisms isolated from Acanthamoeba sp. (gr II). Endocytobiosis Cell Res 12, 185-188.

Jardin, J. B. (1975). Amibes limax vecteurs possible de Mycobacteries et de M. leprae. Acta Leprol 59, 57-67.

Jukes, T. H. \& Cantor, C. R. (1969). Evolution of protein molecules. In Mammalian Protein Metabolism, pp. 21-132. Edited by N. H. Munro. New York: Academic Press.

King, C. H. \& Shotts, E. B. (1988). Enhancement of Edwardsiella tarda and Aeromonas salmonicida through ingestion by the ciliated protozoan Tetrahymena pyriformis. FEMS Microbiol Lett 51, 95-100.

King, C. H., Shotts, E. B., Wooley, R. E. \& Porter, K. G. (1988). Survival of coliforms and bacterial pathogens within protozoa during chlorination. Appl Environ Microbiol 54, 3023-3033.

Laemmli, U. K. (1970). Cleavage of structural proteins during the assembly of the head of bacteriophage T4. Nature 227, 680-685.

Lane, D. J. (1991). 16S/23S rRNA sequencing. In Nucleic Acid Techniques in Bacterial Systematics, pp. 115-176. Edited by E. Stackebrandt \& M. Goodfellow. Chichester: Wiley.

Loy, J. K., Dewhirst, F. E., Weber, W., Frelier, P. F., Garbar, T. L., Tasca, S. I. \& Templeton, J. W. (1996). Molecular phylogeny and in situ detection of the etiological agent of necrotizing hepatopancreatitis in shrimp. Appl Environ Microbiol 62, 3439-3445.

Ly, T. M. C. \& Müller, H. E. (1990). Ingested Listeria monocytogenes survive and multiply in protozoa. J Med Microbiol 33, 51-54.

Michel, R. \& Hauröder, B. (1997). Isolation of an Acanthamoeba strain with intracellular Burkholderia pickettii. Zentbl Bakt 285, 541-557.

Michel, R., Burghardt, H. \& Bergmann, H. (1995a). Natürliche intracelluläre infectionen bei acanthamoeben mit Pseudomonas aeruginosa nach ihrer isolierung aus einer mikrobiologisch beanstandeten trinkwasser-hausinstallation eines krankenhauses. Zentbl Hyg 196, 532-544. 
Michel, R., Müller, K.-D. \& Schmid, E. N. (1995b). Ehrlichia-like organisms (KSL1) observed as obligate intracellular parasites of Saccamoeba species. Endocytobiosis Cell Res 11, 69-80.

Murray, R. G. E. \& Schleifer, K. H. (1994). Taxonomic notes: a proposal for recording the properties of putative taxa of procaryotes. Int J Syst Bacteriol 44, 174-176.

Murray, R. G. E., Brenner, D. J., Colwell, R. R., De Vos, P., Goodfellow, M., Grimont, P. A. D., Pfennig, N., Stackebrandt, E. \& Zavarzin, G. A. (1990). Report of the ad hoc committee on approaches to taxonomy within the Proteobacteria. Int J Syst Bacteriol 40, 213-215.

Neefs, J.-M., Van de Peer, Y., De Rijk, P., Chapelle, S. \& De Wachter, R. (1993). Compilation of small ribosomal subunit RNA structures. Nucleic Acids Res 21, 3025-3049.

Owen, R. J., Legros, R. M. \& Lapage, S. P. (1978). Base composition, size and sequence similarities of genome deoxyribonucleic acids from clinical isolates of Pseudomonas putrefaciens. J Gen Microbiol 104, 127-138.

Page, F. C. (1976). An Illustrated Key to Freshwater and Soil Amoeba. Ambleside, Cumbria: Freshwater Biological Association.

Preer, J. R., Jr \& Preer, L. B. (1984). Endosymbionts of protozoa. In Bergey's Manual of Systematic Bacteriology, vol. 1, pp. 795-811. Edited by N. R. Krieg \& J. G. Holt. Baltimore: Williams \& Wilkins.
Proca-Ciobanu, M., Lupascu, G., Petrovici, A. \& Ionescu, M. D. (1975). Electron microscopic study of a pathogenic Acanthamoeba castellani strain: the presence of bacterial endosymbiotes. Int $J$ Parasitol 5, 49-56.

Rowbotham, T. J. (1980). Preliminary report on the pathogenicity of Legionella pneumophila for freshwater and soil amoebae. J Clin Pathol 33, 1179-1183.

Rowbotham, T. J. (1983). Isolation of Legionella pneumophila from clinical specimens via amoebae, and the interaction of those and other isolates with amoebae. J Clin Pathol 36, 978-986.

Springer, N., Ludwig, W., Amann, R., Schmidt, H. J., Görtz, H.-D. \& Schleifer, K.-H. (1993). Occurrence of fragmented 16S rRNA in an obligate bacterial endosymbiont of Paramecium caudatum. Proc Natl Acad Sci USA 90, 9892-9895.

Stackebrandt, E. \& Goebel, B. M. (1994). Taxonomic note: a place for DNA:DNA reassociation and $16 \mathrm{~S}$ rDNA sequence analysis in the present species definition in bacteriology. Int $J$ Syst Bacteriol 44, 846-849.

Thom, S., Warhurst, D. \& Drasar, B. S. (1992). Association of Vibrio cholerae with fresh water amoebae. J Med Microbiol 36, 303-306.

Tyndall, R. L., Ironside, K. S., Little, C. D., Katz, D. S. \& Kennedy, J. R. (1991). Free-living amoebae used to isolate consortia capable of degrading trichloroethylene. Appl Biochem Biotechnol 28/29, 917-925. 